\title{
Influence of shear velocity on frictional characteristics of rock surface
}

\author{
T N Singh ${ }^{1}$, A K Verma ${ }^{2, *}$, Tanmay $\mathrm{Kumar}^{3}$ and Avi Dutr ${ }^{3}$ \\ ${ }^{1}$ Department of Earth Sciences, Indian Institute of Technology, Powai, Mumbai 400 056, India. \\ ${ }^{2}$ CeRES, The Energy and Resources Institute, Darbari Seth Block, IHC Complex, Lodhi Road, \\ New Delhi 110 003, India. \\ ${ }^{3}$ Institute of Technology, Banaras Hindu University, Varanasi 221 005, India. \\ *e-mail: amverma@iitb.ac.in
}

Understanding the fundamental issues related with the effect of shear velocity on frictional characteristics at the interface of rock surfaces is an important issue. In this paper, strain-rate dependence on friction is investigated in relation to sliding behaviour under normal load. The phenomenon of stick-slip of granite and shaly sandstone with a tribometer at constant rate of strain under normal loads was observed.

Friction at the interface of the rock samples was developed by increasing shear strain at a constant rate by applying constant velocity using the tribometer. For shaly sandstone, state parameters $(a$ and $b)$ played a major role in determining the friction values and roughness of the contact surfaces as well. Higher values of $b$ for shaly sandstone may be attributed to the fact that its surface had a greater number of pronounced asperities. Rubbing between the surfaces does not mean that surface becomes smoother. This is because of variation of friction between surfaces.

\section{Introduction}

A sliding system shows two kinds of motion namely stick-slip (jerky or unsteady) motion and steady (smooth) motion (Blanpied et al 1987; Persson 2000; Mohan et al 2009; Goohpattader and Chaudhury 2010). Steady sliding, as is evident from its name, sliding velocity as well as friction force of the sliding mass does not change with time. Stick-slip motion, on the other hand, involves fluctuating or jerky motion. Unlike steady motion, in stick-slip motion, friction force and velocity of the mass vary periodically during the motion. Stick-slip is generally observed if the mass slips slowly when in contact with the other surface. Chattering of machines, cutting tools, squeaking of doors, melodious sound from stringed instruments such as violin, etc., are results of the stick-slip process. Stick-slip motion occurs because of the interaction between the elastic force and the friction force of the sliding system (Urbakh et al 2004; Rice et al 2009).

Slip movement represents a fairly abrupt increase in the velocity following a measurable slower motion. Stick is the interlocking of asperities present in the rock surface, due to which the motion is prevented (Yamashita and Ohnaka 1991; Matsukawa and Saito 2007). During stick there is an increase in the elastic energy of the system.

Stick-slip depends on a number of factors. The most important factors are: the shear velocity and the quantity and nature of the gouge present at the contact surface (Baumberger and Caroli 2006; Dunham and Rice 2008).

This phenomenon is best understood by an elastic spring and a rigid mass friction model as shown in figure 1.

Keywords. Tribometer; granite; shaly sandstone; state variable; stick-slip friction. 


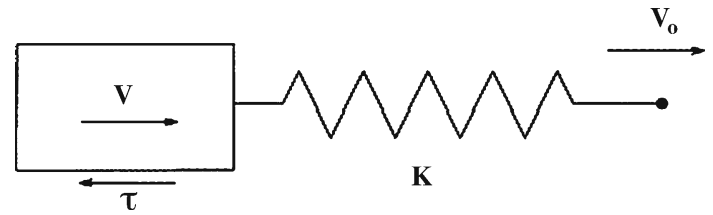

Figure 1. An elastic spring and rigid mass sliding system.

The present setup (tribometer) consists of an elastic spring in series with a rigid block which is in contact with a rigid base having a definite frictional value. The spring represents the elastic energy stored in the rock mass that transmits the tectonic load to a fault simulated by the frictional contact of the two blocks. The free end of the spring is moved at a fixed constant velocity say ' $V$ ', and is controlled by a motor speed representing the steady deformation of the rock mass. In particular, over a certain period the shearing deformation of rock mass builds up the force required to mobilize the existing fault. A part of this force is elastic in nature and is represented by a force of compressed spring in the analogue model.

\section{Experimental setup}

A low-velocity linear tribometer was designed to simulate the friction between two rock surfaces. This experiment can be used to determine the frictional characteristics of different rock surfaces during rubbing. This small-scale experiment can be designed on a large scale for determining the frictional characteristics during fault movement in an earthquake event. The results of this experiment will be useful in understanding the rock movement in a jointed rock and the effect of gouge materials.

A schematic diagram of the tribometer is shown in figure 2. This setup is primarily based on the principle of elastic spring and mass sliding system. According to this principle, if a mass that is connected to an elastic spring slides on a surface, friction force developed at the interface of the mass and the surface will be proportional to stretch or displacement in the spring. The linear slider of the tribometer is attached with a servomotor, which runs at a minimum linear velocity of $1.0 \mu \mathrm{m} / \mathrm{s}$. A load sensor with a maximum capacity of $30 \mathrm{~kg}$ is mounted on the constant moving arm of the linear slider. As the arm moves, the accumulation of stress is recorded by the load sensor and it sends the data to the data acquisition system (DAS). The sampling rate of the recorded data was $5 \mathrm{~Hz}$. The least count of friction value obtained by (DAS) is $0.01 \mathrm{~N}$.

\section{Experimental details}

Two sets of experiments were done for granite and shaly sandstone. First, we studied the frictional change at the interface of rocks by changing the shear velocity, and then we studied the effect of rubbing the rock interface one over other on the friction.

\section{Effect of shear velocity on contact friction}

Two blocks with dimensions $(14 \times 10 \times 3 \mathrm{~cm})$ and $(10 \times 10 \times 3 \mathrm{~cm})$ were prepared each for granite and shaly sandstone. The flat contact surfaces were washed and dried such that all the dust particles were completely removed. The two blocks were placed one over the other and a horizontal force is applied at one of the side surfaces by the arm of the linear slider. The velocity of the arm was varied from $10-80 \mathrm{~mm} / \mathrm{min}$ and the plot of friction $v s$. time was obtained. The total slip distance was $2 \mathrm{~cm}$ in each of the experiments.

The prepared surfaces for granite and shaly sandstones are shown in figures 3 and 4 , respectively.

\section{Effect of rubbing of two blocks on contact friction}

The structure of contact surfaces were changed by rubbing the surface against each other. The rubbing was done 80 times in steps of 10 for each rock under a constant normal force of $300 \mathrm{~N}$, i.e., after 10 rubs the two surfaces were placed together and the upper block was moved at a speed of $10 \mathrm{~mm} / \mathrm{s}$ for $2 \mathrm{~min}$ so that the total displacement of the upper block is $120 \mathrm{~cm}$. Again the surfaces were rubbed 10 times and the two surfaces were placed one over the other and the upper block was moved at a constant speed of $10 \mathrm{~mm} / \mathrm{s}$ for $2 \mathrm{~min}$. This procedure was carried out 8 times. As the number of rub was increased there was formation and accumulation of gouge at the contact surface due to which the surface friction changed. Care was taken such that the gouge formed during rubbing remained between the surfaces and it was not blown off. Figure 5 shows the relative position and the interface of the blocks.

\section{Discussion and conclusion}

The friction value is governed by two factors, i.e., shear velocity and the state parameters such as 


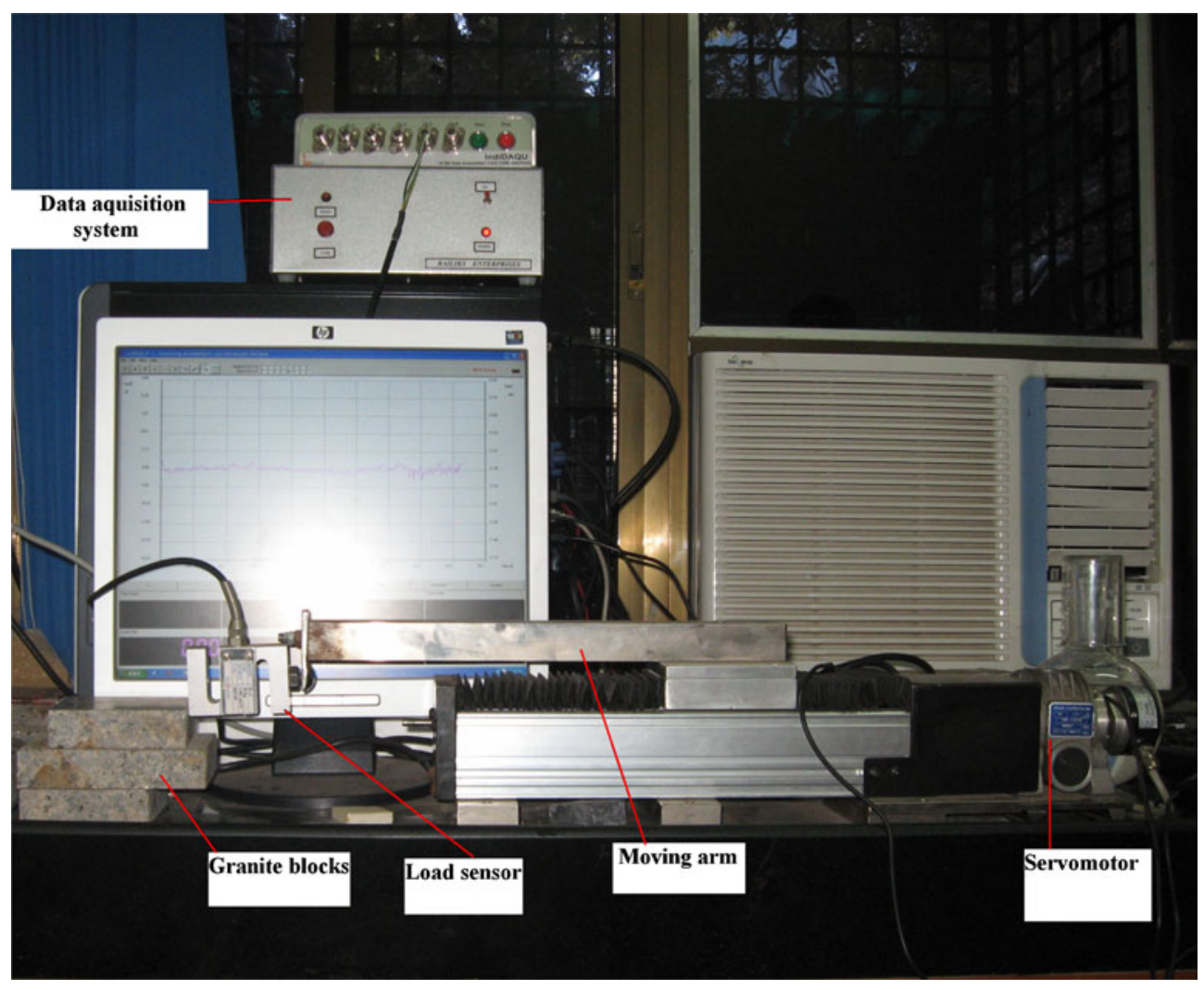

Figure 2. Schematic diagram of the tribometer.

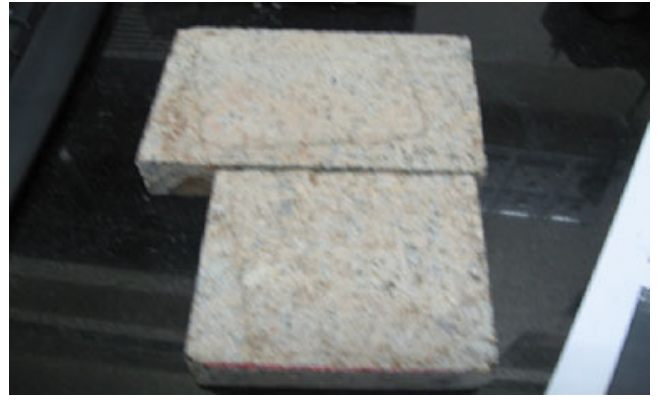

Figure 3. Surface preparation for granite.

grain size, roughness, cohesive strength, nature and thickness of gouge present between the sliding surfaces.

If the state parameter is considered to be a constant, the increase in shear velocity can affect the friction in two ways. The friction may increase, and this kind of friction is called velocity strengthening friction (Martins et al 1995; Ranjith and Rice 2001). The rocks which show this property are more prone to earthquakes if faults are present in them because as the friction increases, sliding becomes more unstable and jerky because of large amount of accumulated frictional energy and its sudden release. The friction may also decrease and

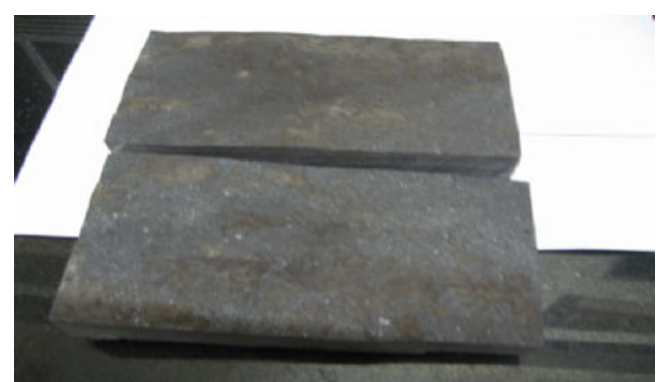

Figure 4. Surface preparation for shaly sandstone.

is called the velocity weakening friction. The rocks showing this property show smoother and more stable motion during sliding (it accumulates less frictional energy).

It is very clear from figure 6 that there is a jump in the value of friction with a sudden change in velocity, if the state parameter remains constant (Prakash and Clifton 1993).

The value of state parameter $(\theta)$ also changes with the change in velocity, which in turn affects friction. However, the effect is negative and very smooth as shown in figure 7.

Combined effects of velocity and state parameters on the sliding resistance is given in figure 8 . 


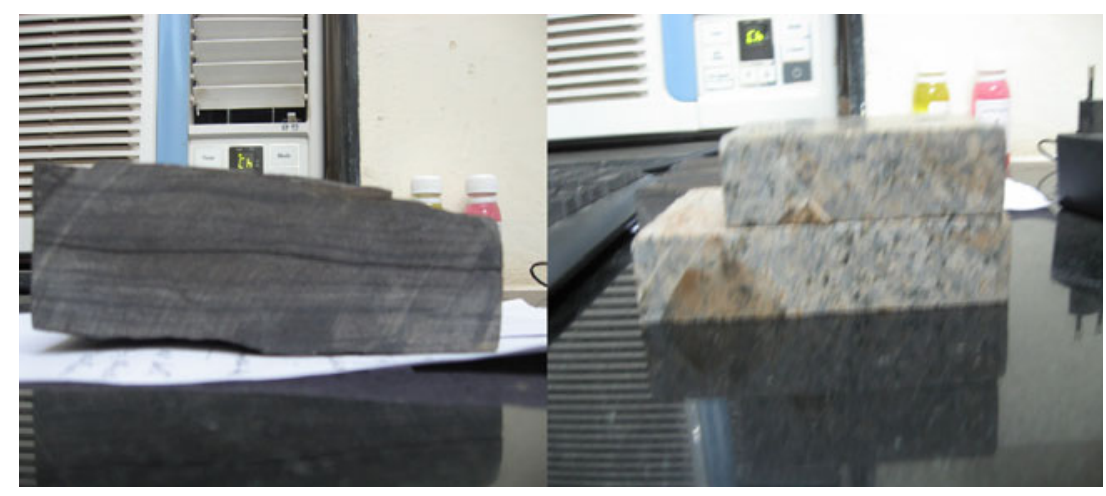

Figure 5. Interface of both granite and shaly sandstone.

The dependence of sliding resistance on rate and state is mathematically expressed as:

$$
\tau=\sigma_{0}\left[\mu_{0}+a \cdot \ln \underset{\downarrow}{\downarrow}\left(V / V_{0}\right)+b \cdot \ln \left(V_{0} \times \theta / D_{\mathrm{c}}\right)\right]
$$

where $\tau$ is the shear stress $(\mathrm{Pa}), \sigma_{0}$ the normal stress $(\mathrm{Pa}), \mu_{0}$ the initial coefficient of friction, $a$, $b$ the experimentally determined constant, $V$ the displacement rate $(\mathrm{m} / \mathrm{s}), \theta$ the 'state' variables, $D_{\mathrm{c}}$ the critical slip distance and $V_{0}$ the initial displacement rate $(\mathrm{m} / \mathrm{s})$.

In order to study the velocity effect on friction for shaly sandstone, the two blocks were kept one over the other and the point of application of force was given the shear velocity of $1 \mathrm{~mm} / \mathrm{min}$. After $96 \mathrm{~s}$ the velocity of the cantilever arm was increased suddenly from $1-100 \mathrm{~mm} / \mathrm{min}$ and the friction suddenly decreased from 6.8-4 N, an appreciable decrease in friction and within $2 \mathrm{~s}$ the friction again started gaining its value and remained on an average of $4.5 \mathrm{~N}$ with same fluctuations as shown in figure 9. The normal force on the lower block is only because of the weight of the upper block.

Friction value changes with time and there are lots of narrow crests and troughs, the peak point of which represents slip point and stick point respectively describing the stick-slip phenomenon (figure 9). It also represents the effect of sudden change of velocity on friction. Figure 10 shows the physical law governing friction. Comparing figures 9 and 10, it was found that values of constants $a$ and $b$ are 0.046 and 0.1604 , respectively.

Constants $a$ and $b$ are related to change in rate and state variables respectively. $a$ is the change in the rate of velocity and signifies the rate of change of friction. $b$ is the state variable and signifies change in fracture pattern and consequently roughness of the surface.

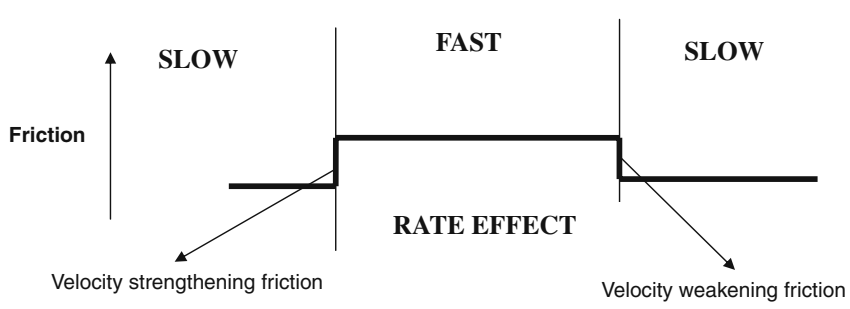

Figure 6. Effect of velocity on friction for constant state.

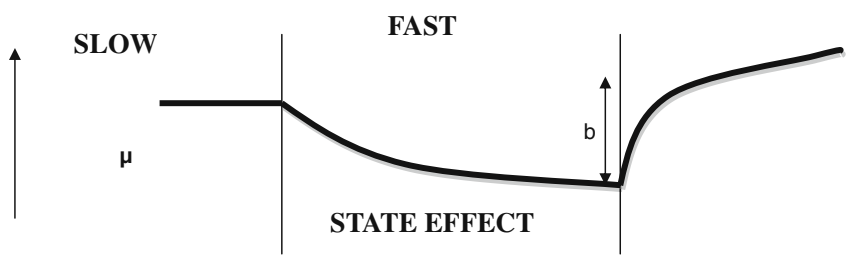

Figure 7. The effect of velocity on friction for variable state.

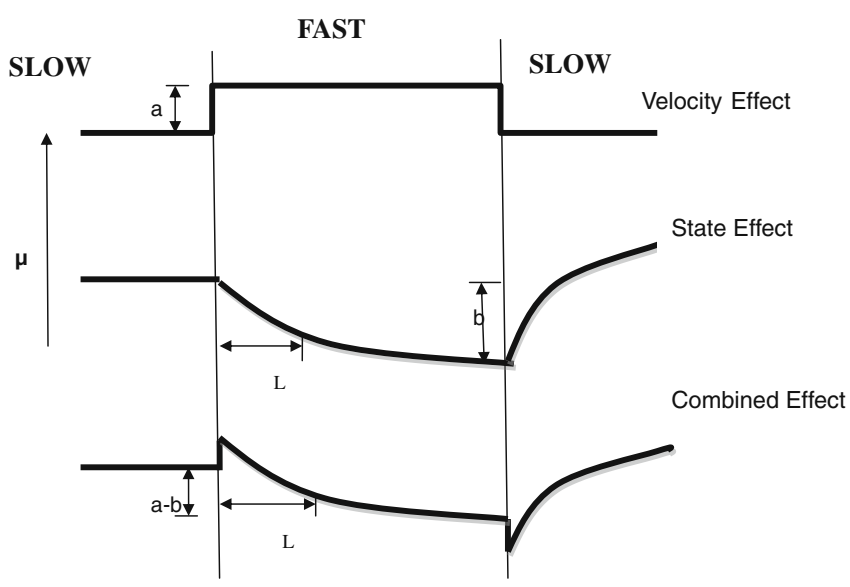

SLIP

Figure 8. Combined effect of velocity and state parameters on friction. 


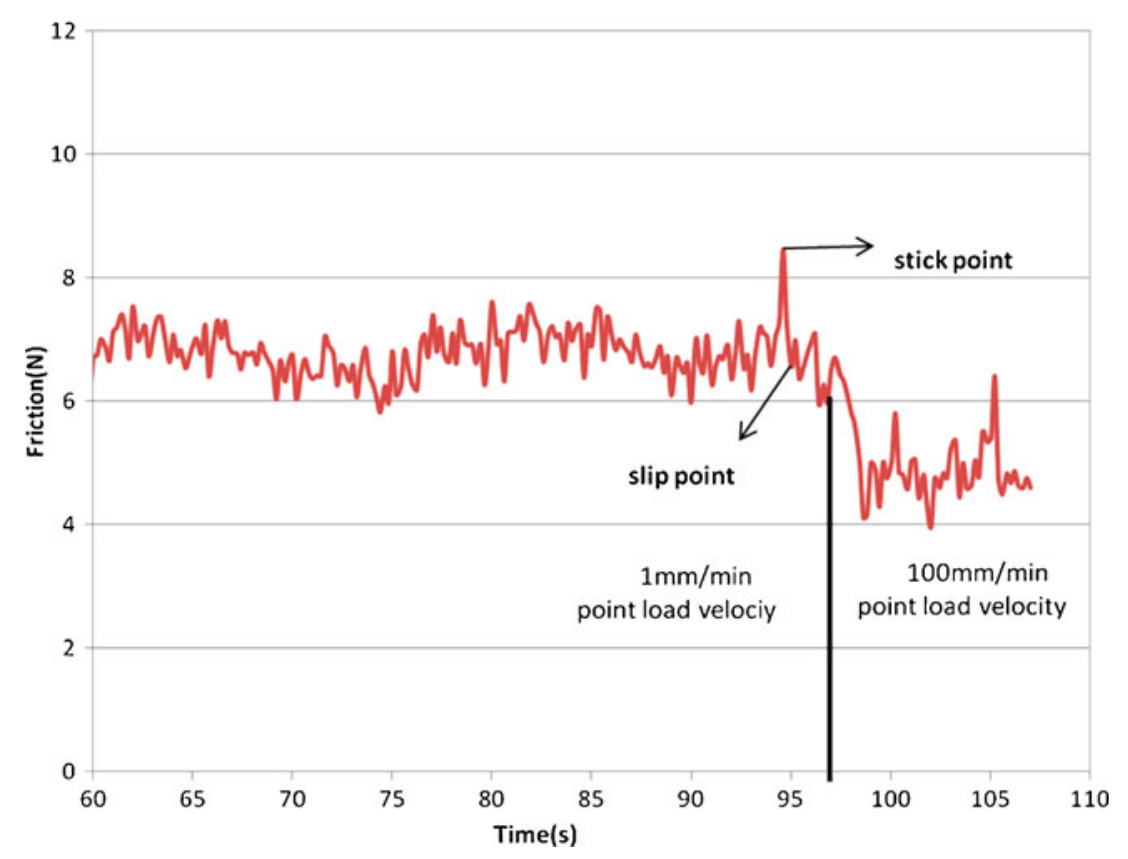

Figure 9. Variation of friction with time for shaly sandstone.

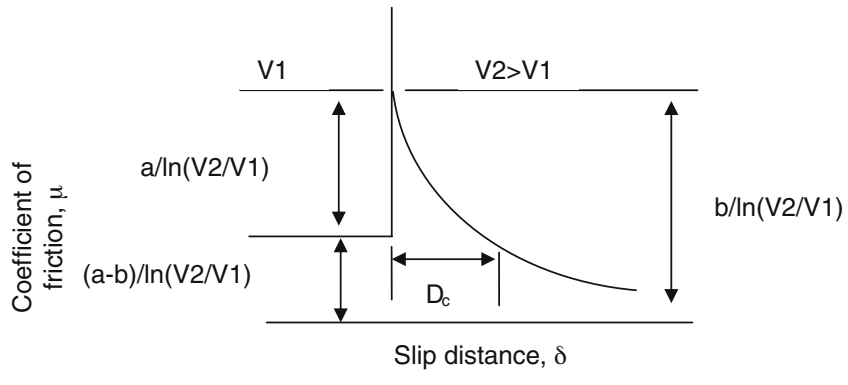

Figure 10. Physical law governing friction.

The limiting value of $b$ needs to be of the order of 0.001 but in our case it is around 0.1604. This means that in our experiment the state parameter played a major role in determining the friction value. The higher value of $b$ indicates that the contact surface is very rough; this is because of coarser grain size and the presence of a greater number of asperities.

During the course of the experiment it was found that when the velocity of slip was abruptly changed to a higher value, the frictional resistance did not stabilize immediately. It has been observed that a critical displacement $\left(d_{c}\right)$ is required before the friction stabilizes at a value characteristic of a new slip velocity. For shaly sandstone, the value of $d_{\mathrm{c}}$ was found to be $3.67 \mathrm{~mm}$.

As the friction decreases with increase in velocity (table 1), it can be concluded that the shaly sandstone is a velocity weakening material and thus less energy will be released during fault movement with shaly sandstone.
Table 1. Average friction of the contact surfaces for shaly sandstone.

\begin{tabular}{lc}
\hline $\begin{array}{l}\text { Shear velocity } \\
(\mathrm{mm} / \mathrm{s})\end{array}$ & $\begin{array}{c}\text { Average } \\
\text { friction }(N)\end{array}$ \\
\hline 10 & 6.868 \\
20 & 5.146 \\
\hline
\end{tabular}

A similar experiment was also performed for granite (figure 11).

Values of $a, b$ and $d_{\mathrm{c}}$ for granite were found to be $0.0794,0.0984$ and 0.667 , respectively.

Comparison of values of $a$ and $b$ for granite and shaly sandstone is shown in table 2 .

The higher value of $b$ for shaly sandstone may be attributed to the fact that its surface had greater number and more pronounced asperities. Also the hardness and cohesive strength of granite is greater than that of shaly sandstone.

Whether the system will show stable sliding or not, it depends on the stiffness of the system $(k)$. The mathematical formulation for calculation of critical stiffness $\left(k_{\mathrm{cr}}\right)$ of a spring slider system is given as (Rice and Ruina 1983):

$$
k_{\mathrm{cr}}=-\frac{V}{L} \frac{\mathrm{d} \tau^{s s}(V)}{\mathrm{d} V}\left[1+\frac{m V}{L \partial F(V, \theta) / \partial V}\right],
$$

where $k_{\text {cr }}$ is the critical stiffness, $V$ the speed of steady slip, $\tau^{\mathrm{ss}}(V)$ the steady state value of $z$ for slip at constant $k, \tau=F(V, \theta), L$ the characteristic relaxation slip for state variable $\theta$ and $m$ is the mass of the slider. 


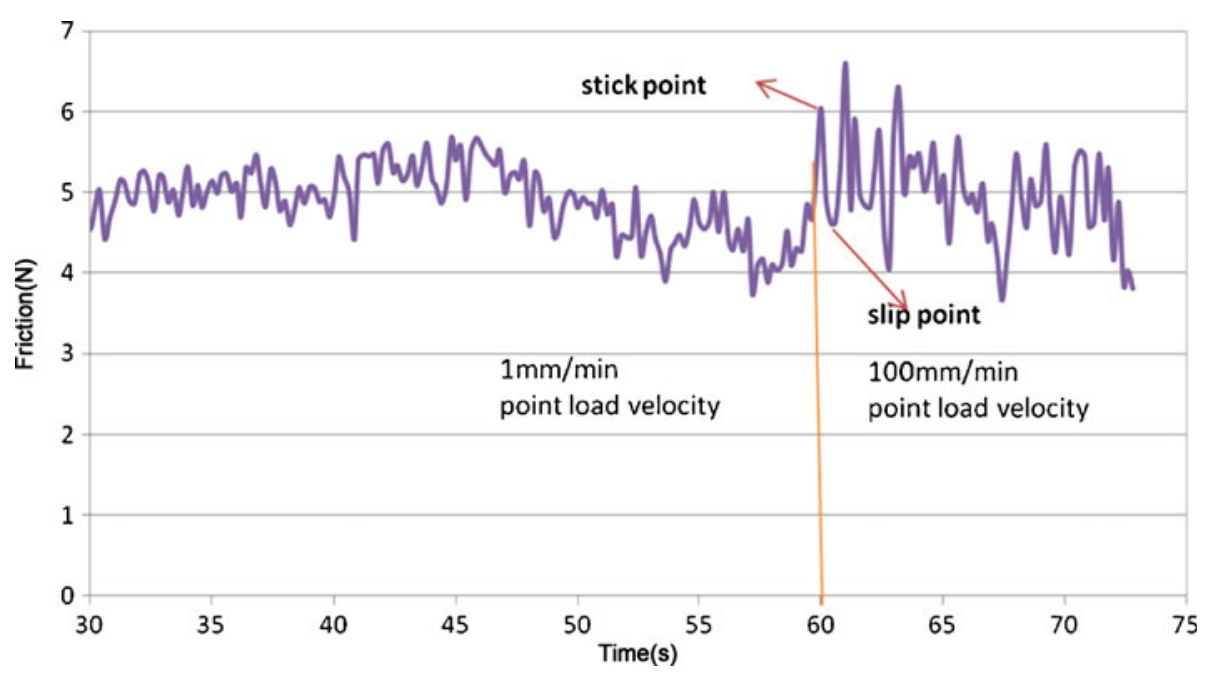

Figure 11. Variation of friction with time for granite.

Table 2. Comparison of constants $a$ and $b$ for granite and shaly sandstone.

\begin{tabular}{lcc}
\hline Rock type & Value of $a$ & Value of $b$ \\
\hline Granite & 0.0794 & 0.0984 \\
Shaly sandstone & 0.046 & 0.1604 \\
\hline
\end{tabular}

If the stiffness coefficient $k<k_{\text {cr }}$ there is a stable sliding. If $k>k_{\mathrm{cr}}$, there is an unstable sliding and if $k=k_{\text {cr }}$ the sliding is oscillatory.

On increasing the slip velocity it has been observed that stiffness of the system also increases, jump in friction value during stick-slip decreases and hence the system gains more stability. The randomness of dataset decreases and the data points tend to be very close to the mean value. This observation can be validated by standard deviation of data observed at 10, 20, 30, 40, $50,60 \mathrm{~mm} / \mathrm{min}$, which when calculated, shows a decreasing trend. The standard deviation and $P$-values of the observed data for granite is listed in table 3 .

The $P$-values of observations at 10,20 and $30 \mathrm{~mm} / \mathrm{min}$ is less than 0.0001 , which indicates that the series of data does not alter enough (too few runs) or verify too much (too many runs). It means that during the movement of block at these velocities the state behaviour remains almost constant throughout the experiment.

Similar trend was also seen for shaly sandstone. Table 4 shows the standard deviation and $P$-value for shaly sandstone.

In this case $P$-values are less than 0.0001 except for $80 \mathrm{~mm} / \mathrm{s}$ which indicates that the randomness of the observed data is too low or at a given velocity the state behaviour is almost constant.
With increase in the speed of the cantilever arm the stiffness of system increases, the system gains stability and the amplitude of stick slip decreases although the frequency of its occurrence remains almost the same. As the asperities present at the contact surface becomes interlocked the upper block experiences some retarding force and so, the velocity of the upper block decreases, its momentum decreases and it applies some force at the interlock. The external force needed to overcome interlocking decreases with increasing velocity because the momentum increases. The velocity of the block after it overcomes stick-slip also becomes relatively lesser. So the external force needed to make the block's velocity equal to the arm's velocity is higher. The peak of the stick decreases in magnitude and that of the slip point increases, and as a result the amplitude of the stick slip is lowered.

In order to study the effect of gouge between contact surfaces, the two surfaces were rubbed against each other and eight sets of friction values have been obtained. For each set, the contact surfaces were rubbed ten times and the average friction was calculated for granite from each set of observation (tables 5, 6 and 7).

Figure 12 shows the average friction vs. number of rubs which is a sinusoidal type of curve for granitic rock while figure 13 shows average friction vs. number of rubs for shaly sandstone. It means that on increasing the rubs it cannot be concluded that the surface becomes smoother continuously because friction value is sometimes increasing and sometimes decreasing. However, the gouge is being continuously formed between the contact surfaces. This is because the influence of gouge presumably depends on the nature and specific behaviour of 
Table 3. Standard deviation and P-values of observed data for granite.

\begin{tabular}{|c|c|c|c|c|c|c|}
\hline $\begin{array}{l}\text { Test run for } \\
\text { randomness }\end{array}$ & $10 \mathrm{~mm} / \mathrm{min}$ & $20 \mathrm{~mm} / \mathrm{min}$ & $30 \mathrm{~mm} / \mathrm{min}$ & $40 \mathrm{~mm} / \mathrm{min}$ & $50 \mathrm{~mm} / \mathrm{min}$ & $80 \mathrm{~mm} / \mathrm{min}$ \\
\hline$\overline{\text { Observations }}$ & 601 & 301 & 201 & 151 & 121 & 100 \\
\hline $\begin{array}{l}\text { Number of observations } \\
\text { below mean value }\end{array}$ & 299 & 145 & 98 & 75 & 56 & 51 \\
\hline $\begin{array}{l}\text { Number of observations } \\
\text { above mean value }\end{array}$ & 302 & 156 & 103 & 76 & 65 & 50 \\
\hline Mean & 5.1427 & 5.1824 & 5.1245 & 5.2328 & 5.1781 & 5.4614 \\
\hline$E(R)$ & 301.4925 & 151.2990 & 101.4378 & 76.4967 & 61.1653 & 51.4950 \\
\hline Std deviation & 12.2471 & 8.6486 & 7.0666 & 6.1233 & 5.4465 & 4.9993 \\
\hline$P$-value (two-tailed) & $<0.0001$ & $<0.0001$ & $<0.0001$ & 0.0004 & $<0.0001$ & 0.0019 \\
\hline
\end{tabular}

Table 4. Standard deviation and P-value of shaly sandstone.

\begin{tabular}{|c|c|c|c|c|c|c|}
\hline $\begin{array}{l}\text { Run test for } \\
\text { randomness }\end{array}$ & $10 \mathrm{~mm} / \mathrm{min}$ & $20 \mathrm{~mm} / \mathrm{min}$ & $30 \mathrm{~mm} / \mathrm{min}$ & $40 \mathrm{~mm} / \mathrm{min}$ & $50 \mathrm{~mm} / \mathrm{min}$ & $80 \mathrm{~mm} / \mathrm{min}$ \\
\hline$\overline{\text { Observations }}$ & 600 & 300 & 200 & 150 & 120 & 75 \\
\hline $\begin{array}{l}\text { Number of observations } \\
\text { below mean value }\end{array}$ & 415 & 189 & 122 & 85 & 68 & 40 \\
\hline $\begin{array}{l}\text { Number of observations } \\
\text { above mean value }\end{array}$ & 185 & 111 & 78 & 65 & 52 & 35 \\
\hline Mean & 5.647 & 5.899 & 5.748 & 5.618 & 5.647 & 5.361 \\
\hline$E(R)$ & 256.9167 & 140.8600 & 96.1600 & 74.6667 & 59.9333 & 38.3333 \\
\hline Std deviation & 10.4360 & 8.0593 & 6.7102 & 5.9939 & 5.3564 & 4.2814 \\
\hline$P$-value (two-tailed) & $<0.0001$ & $<0.0001$ & $<0.0001$ & $<0.0001$ & $<0.0001$ & 0.0001 \\
\hline
\end{tabular}

Table 5. Average friction value for the number of rubs for granite.

\begin{tabular}{cc}
$\begin{array}{l}\text { Number } \\
\text { of rubs }\end{array}$ & $\begin{array}{c}\text { Average friction } \\
\text { value }(N)\end{array}$ \\
\hline 0 & 5.454 \\
10 & 4.607 \\
20 & 4.293 \\
30 & 5.256 \\
40 & 4.082 \\
50 & 4.882 \\
60 & 5.623 \\
70 & 4.707 \\
80 & 5.053 \\
\hline
\end{tabular}

Table 6. Average friction value for the number of rubs for shaly sandstone.

\begin{tabular}{cc}
\hline $\begin{array}{l}\text { Number } \\
\text { of rubs }\end{array}$ & $\begin{array}{c}\text { Average friction } \\
\text { value }(N)\end{array}$ \\
\hline 0 & 5.645 \\
10 & 5.536 \\
20 & 5.711 \\
30 & 5.757 \\
40 & 5.942 \\
50 & 5.655 \\
60 & 5.177 \\
70 & 5.402 \\
80 & 5.519 \\
\hline
\end{tabular}

Table 7. Standard deviation and P-values for granite.

\begin{tabular}{|c|c|c|c|c|c|c|}
\hline $\begin{array}{l}\text { Run test for } \\
\text { randomness }\end{array}$ & 10 rubs & 20 rubs & 30 rubs & 40 rubs & 50 rubs & 80 rubs \\
\hline$\overline{\text { Observations }}$ & 600 & 600 & 600 & 600 & 600 & 600 \\
\hline $\begin{array}{l}\text { Number } \\
\text { of observations } \\
\text { below mean value }\end{array}$ & 317 & 312 & 302 & 309 & 304 & 313 \\
\hline $\begin{array}{l}\text { Number } \\
\text { of observations } \\
\text { above mean value }\end{array}$ & 283 & 288 & 298 & 291 & 296 & 287 \\
\hline Mean & 4.6079 & 4.2912 & 5.2499 & 4.0807 & 4.8805 & 5.0554 \\
\hline$E(R)$ & 300.0367 & 300.5200 & 300.9867 & 299.7860 & 300.9467 & 300.4367 \\
\hline Std deviation $(R)$ & 12.1979 & 12.2176 & 12.2367 & 12.2080 & 12.2350 & 12.2142 \\
\hline$P$-value (two-tailed) & $<0.0001$ & $<0.0001$ & $<0.0001$ & $<0.0001$ & $<0.0001$ & $<0.0001$ \\
\hline
\end{tabular}




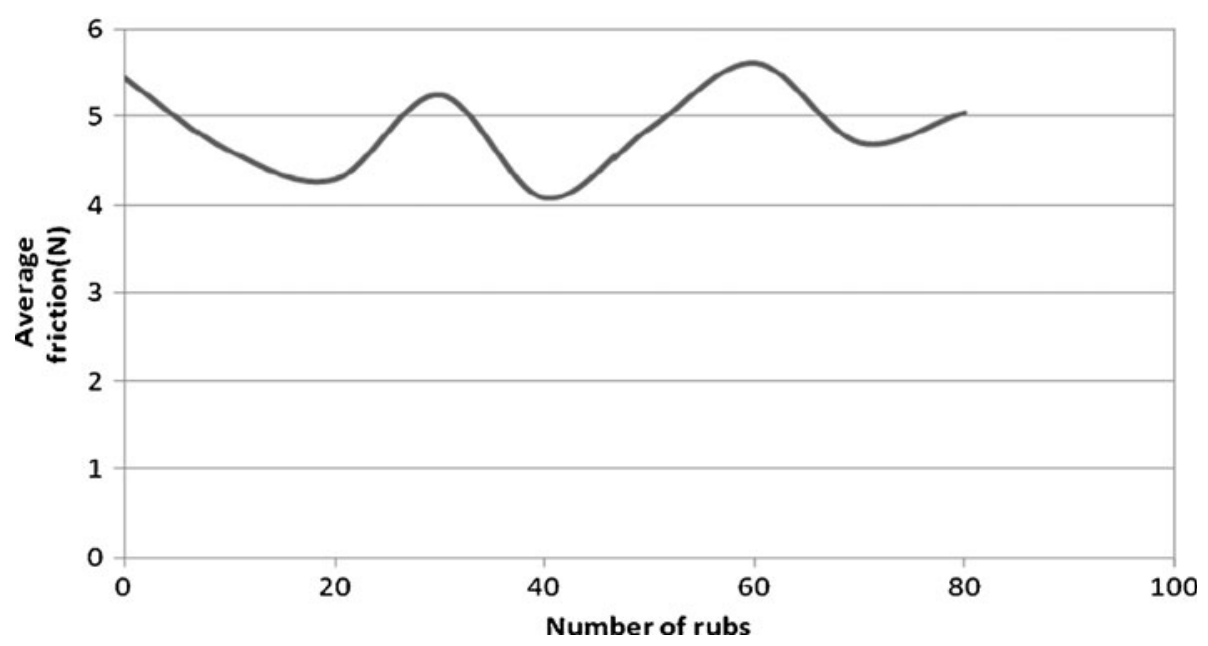

Figure 12. Variation of average friction with number of rubs for granite.



Figure 13. Variation of average friction with number of rubs for shaly sandstone.

the gouge layer. Friction also depends on the distribution of gouge over the surface. If there is accumulation of gouge or formation of new asperities the friction value increases. On the other hand, if the asperities are filled by gouge material friction decreases.

Standard deviation of friction from mean value is the measure of stick-slip because the deviation of friction from mean value is due to stick-slip. In table 7 , it is clear that standard deviation is not showing any particular trend. It is sometimes increasing and at other times decreasing because gouge does not always inhibit the stickslip. The stick-slip may increase due to accumulation of coarse-grained material on the surface. So the quantity of gouge cannot be correlated uniquely with the presence or absence of stick slip.

This experiment can be useful in understanding the effect of gouge material on the frictional behaviour between rock surfaces. Values of constants like $b$ can be useful for predicting the pattern of fracture developed in the rock surface during rock sliding.
Stick-slip behavior is very prominent during landslide and earthquake and hence its understanding will help to reduce the frequent occurrence of natural hazards.

\section{References}

Baumberger T and Caroli C 2006 Solid friction: From stickslip down to pinning and aging; Adv. Phys. 55 273-348.

Blanpied M L, Tullis T E and Weeks J D 1987 Frictional behavior of granite at low and high sliding velocities; Geophys. Res. Lett. 14 554-557.

Dunham E M and Rice J R 2008 Earthquake slip between dissimilar poroelastic materials; J. Geophys. Res. 113 B09304, doi: 10.1029/2007JB005405.

Goohpattader P S and Chaudhury M K 2010 Diffusive motion with nonlinear friction: Apparently Brownian; $J$. Chem. Phys. 133 024702, doi: 10.1063/1.3460530.

Martins J A C, Guimaraes J and Faria L O 1995 Dynamic surface solutions in linear elasticity and viscoelasticity with frictional boundary conditions; J. Vibration Acoust. Trans. ASME 117 445-451.

Matsukawa H and Saito T 2007 Friction, stick-slip and earthquake; Lecture Notes Phys. 705 169-189. 
Mohan C B, Divakar C, Venkatesh K, Gopalakrishna K, Mahesh Lohith K S and Naveen T N 2009 Design and development of an advanced linear reciprocating tribometer, Wear, (5-8) 267, 17th International Conference on Wear of Materials, pp. 1111-1116, ISSN 0043-1648, doi: 10.1016/j.wear.2009.01.047.

Persson B N J 2000 Sliding friction: Physical principles and applications, (Heidelberg: Springer) pp. 2124-133.

Prakash V and Clifton R J 1993 Time resolved dynamic friction measurements in pressure-shear; In: Experimental techniques in the dynamics of deformable solids AMD, (ed.) K T Ramesh (New York: ASME) 165 $33-48$.

Ranjith K and Rice J R 2001 Slip dynamics at an interface between dissimilar materials; J. Mech. Phys. Solids 49 341-361.
Rice J R, Dunham E M and Noda H 2009 Thermo- and hydro-mechanical processes along faults during rapid slip; In: Meso-scale shear physics in earthquake and landslide mechanics; Proceedings of the Batsheva de Rothschild Seminar on Shear Physics at the Meso-scale in Earthquake and Landslide Mechanics, Ein Gedi, Israel, 26-30 January 2009 (eds) Hatzor Y, Sulem J and Vardoulakis I, CRC Press, pp. 3-16.

Rice J R and Ruina A L 1983 Stability of steady frictional slipping; J. Appl. Mech. 50 343-349.

Urbakh M, Klafter J, Gourdon D and Israelachvili J 2004 The nonlinear nature of friction; Nature 430 525-528.

Yamashita T and Ohnaka M 1991 Nucleation process of unstable rupture in the brittle regime: A theoretical approach based on experimentally inferred relations; $J$. Geophys. Res. 96 8351-8367. 